\title{
Electromagnetic Force Analysis of Eccentric Axial Flux Permanent Magnet Machines
}

\author{
Qiaoshan Li (D), Bingyi Zhang, and Aimin Liu \\ School of Electrical Engineering, Shenyang University of Technology, Shenyang 110870, China \\ Correspondence should be addressed to Qiaoshan Li; liqiaoshan@sut.edu.cn
}

Received 1 February 2020; Accepted 6 April 2020; Published 29 April 2020

Academic Editor: Andrés Sáez

Copyright (C) 2020 Qiaoshan Li et al. This is an open access article distributed under the Creative Commons Attribution License, which permits unrestricted use, distribution, and reproduction in any medium, provided the original work is properly cited.

Based on Schwarz-Christoffel mapping, this paper presents a fast analytical method to analyze the electromagnetic force of eccentric axial flux permanent magnet machines, considering static, dynamic, and mixed eccentricities. A quasi-3D model of an axial flux permanent magnet machine is established, and the magnetic field is obtained by Schwarz-Christoffel mapping. The electromagnetic force density is obtained by the Maxwell stress tensor method, and the electromagnetic force density is used to characterize the variation of electromagnetic force. The distribution law of electromagnetic force is investigated. The calculated results are verified by the finite element method, which has shown that the method in this paper can be widely used in the analysis of axial flux permanent magnet machines.

\section{Introduction}

Due to high efficiency, compact structure, and good heat dissipation performance, axial flux permanent magnet (AFPM) machines are widely used in electric vehicles, flywheel energy storage, and other fields [1-3]. Because of the unique structural characteristics of an AFPM machine, the eccentricity of a stator and rotor is easy to occur in the assembly process, which will bring adverse effects. Therefore, it is necessary to study the magnetic field of the eccentric AFPM machine.

In the calculation of electromagnetic force, the commonly used methods are the virtual displacement method and Maxwell stress tensor (MST) method. The magnitude and direction of electromagnetic force can be obtained by the virtual displacement method, but the specific distribution of electromagnetic force inside the machine cannot be found. When the magnetic induction intensity is solved, the distribution of electromagnetic force at different locations can be obtained by the MST method, which is widely used in the calculation of electromagnetic force $[4,5]$.

In the application of the MST method, the analysis of magnetic field is the key point. Magnetic field analysis methods of AFPM machines include equivalent magnetic circuit (EMC) method, finite element method (FEM), and analytical method. The FEM is the most accurate one at present [6-8]. However, because of its structural characteristics, AFPM motor needs 3D model analysis. This usually requires a higher configuration of computer, and the solution time is too long, which is disadvantageous in the early stage of motor design.

The accuracy of the EMC method depends directly on the rationality of the establishment of the EMC; meanwhile, the establishment of the EMC is closely related to the structure of the machine, which limits the accuracy and generality of the method.

The analytical method has higher precision and shorter time-consuming. The exact subdomain method can perform analytical calculation of the magnetic field with high accuracy of the solution [9]; however, the process is too complicated. The conformal transformation method can transform problems in complex regions into simpler ones, Schwarz-Christoffel mapping is a conformal transformation of the upper half-plane onto the interior of a simple polygon, whose boundary can be composed of straight lines, line segments, or rays [10], and this provides a convenient condition for us to calculate the slot effect of AFPM machines. When applying Schwarz-Christoffel mapping to 
magnetic field analysis of electrical machines, some studies equated the depth of stator slots to infinite depth in order to facilitate the calculation of mapping function [11]. However, in practice, the ratio of slot depth to slot width is not large enough to make the assumption of infinite depth slot in many AFPM machines, so the research method above will bring errors to the calculation of results. In Reference [12], the magnetic field of an AFPM machine with slots of limited depth is analyzed by using the Schwarz-Christoffel mapping method. In Reference [13], conformal transformation and the EMC method are combined to study the unbalanced force of a surface-mounted permanent magnet motor with radial flux under an eccentric state. In Reference [14], air-gap flux density is calculated by using a combination of Maxwell's equations and the Schwarz-Christoffel mapping method, the structure of static angular eccentricity can be directly drawn by the Schwarz-Christoffel mapping, and then an analytical model is proposed to study the static angular eccentricity of an AFPM machine. A proper modeling method plays an important role in the process of analytical calculation in AFPM machines. In Reference [15], the quasi-3D method is introduced, which can transform the $3 \mathrm{D}$ geometry of an axial flux machine to a 2D geometry. By modeling the investigated machine with the quasi-3D method, the calculation needs shorter computation time compared with the FEM while ensuring the accuracy.

On the basis of the above research, we propose a method for calculating the electromagnetic force of AFPM machines with considerable time savings. The magnetic field of an AFPM machine under no-load condition is analyzed using Schwarz-Christoffel mapping in this paper, and the Maxwell stress tensor method is used to obtain the electromagnetic force distribution of the AFPM machine, considering different eccentricity faults, including static, dynamic, and mixed eccentricities. The investigated AFPM machine is shown in Figure 1, and its parameters can be found in Table 1. The electromagnetic force acting on the stator and rotor is solved separately. For convenience, the following assumptions are made: (a) the core is unsaturated and the permeability is infinite; (b) eddy current loss is neglected; and (c) end effect is neglected.

\section{Magnetic Field and Electromagnetic Force}

The quasi-3D method is used to model the investigated AFPM machine during the process of calculating the magnetic field. The specific steps are shown in Figure 2.

The average radius $R_{k}$ of the layer $K(k=1,2,3, \ldots, N)$ selected is calculated as

$$
R_{k}=R_{i}+\frac{R_{o}-R_{i}}{2 N}(2 k-1),
$$

where $R_{i}$ and $R_{o}$ are the internal and external radii of the machine.

In this paper, the magnetic field at an average radius $(k=(N+1) / 2)$ of the machine is studied; the value of $k$ is brought into equation (1) to calculate the location of the investigated layer, and the result is $R=157.75 \mathrm{~mm}$.
SC mapping is carried out with the help of the SC toolbox of MATLAB. The machine model is transformed into three planes, as shown in Figure 3. The complex variables are used in the calculation of the magnetic field by the proposed method. In Figure 3(a), the 2D model that obtained from the quasi-3D method is shown in the $\mathrm{V}$-plane. Next, a rectangle domain in the $\mathrm{W}$-plane is mapped to the slotted air-gap polygon in the $\mathrm{V}$-plane, and there is a strip air-gap as shown in Figure 3(b). Then, a mapping is used to map the interior of an annular domain in the T-plane to a rectangular domain in the $\mathrm{W}$-plane. The reason for choosing the final transformation is that periodic boundary condition will automatically satisfy, as shown in Figure 3(c). Moreover, Hague's field solution in the annular air-gap is available [12]. So, the transformation is done among these 3 planes.

The air-gap flux density BV in the $\mathrm{V}$-plane is obtained as

$$
B_{V}=B_{T}\left(\frac{\partial T}{\partial V}\right)^{*}=B_{T} \frac{1}{(\partial V / \partial T)^{*}}=B_{T} \frac{1}{(\partial V / \partial W \cdot \partial W / \partial T)^{*}}
$$

where $V, W$, and $T$ are any functions of $v=v+z i$, $w=x+y i$, and $\zeta=\chi+\sigma i ; \partial V / \partial W, \partial W / \partial T, \partial V / \partial T$, and $\partial T / \partial V$ are partial derivatives; “*” represents conjugate function; $B_{v}$ and $B_{T}$ are both scalars; and $B_{T}$ is given in Reference [12].

Electromagnetic force can be obtained by integrating electromagnetic force density (EFD). In an AFPM machine, the area that the electromagnetic force acts on is certain, so the electromagnetic force directly depends on the EFD. Therefore, in this paper, we directly focus on the study of $\mathrm{EFD}$, in order to get the variation regularity of the electromagnetic force.

Applying the MST method, the axial $f_{\mathrm{z}}$ and tangential $f_{\mathrm{t}}$ components of EFD are given by

$$
\begin{gathered}
f_{z}=\frac{B_{z}^{2}-B_{t}^{2}}{2 \mu_{0}}, \\
f_{t}=\frac{B_{z} \cdot B_{t}}{\mu_{0}},
\end{gathered}
$$

where $B_{\mathrm{z}}$ and $B_{\mathrm{t}}$ are the axial and tangential components of the air-gap flux density.

\section{Eccentricity Description}

Eccentricity often occurs due to assembly and other factors in an AFPM machine, resulting in uneven air-gap of the machine. The types of eccentricity can be divided into the following categories: static eccentricity (SE), dynamic eccentricity (DE), and mixed eccentricity (ME). It is noticed that the stator physical axis, the rotor physical axis, and the rotor rotating axis do not coincide with each other in $\mathrm{ME}$, as shown in Figure 4.

Figure 5 presents parameters required in the analysis of eccentricity. In order to study the electromagnetic force in different directions more rationally, three reference coordinate systems are introduced as follows: 


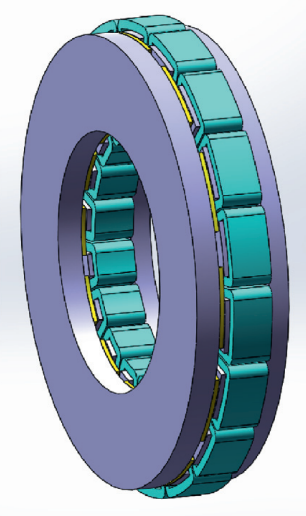

(a)

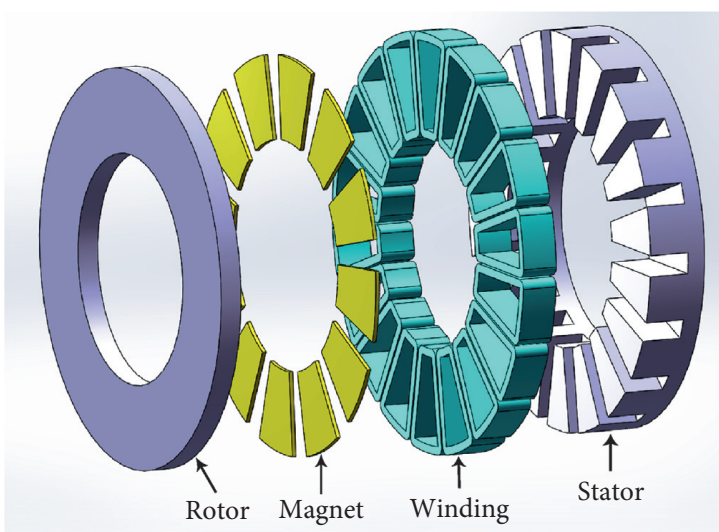

(b)

FIgURE 1: Construction (a) and exploded view (b) of the investigated AFPM machine.

TABle 1: Parameters of the investigated machine.

\begin{tabular}{lc}
\hline Parameters & Values \\
\hline Rated power $(\mathrm{kW})$ & 1.5 \\
Rated speed $(\mathrm{r} / \mathrm{min})$ & 150 \\
Number of stator slots & 18 \\
External radius of stator $(\mathrm{mm})$ & 200 \\
Internal radius of stator $(\mathrm{mm})$ & 115.5 \\
Number of poles & 12 \\
Axial thickness of PM (mm) & 4 \\
Magnet-arc to pole-pitch ratio & 0.71 \\
\hline
\end{tabular}

(1) Machine coordinate system (MCS), based on the stator and rotor under ideal condition

(2) Stator coordinate system (SCS), based on the stator in every eccentricity fault

(3) Rotor coordinate system (RCS), based on the rotor in every eccentricity fault, and the reference is MCS when the reference frame is not specified in the following research

The eccentricity factor (EF) is introduced to describe the degree of eccentricity, and the static eccentricity factor (SEF) is

$$
\mathrm{SEF}=\frac{r_{S}}{g_{0}} \times 100 \%,
$$

where $g_{0}$ is the air-gap length under ideal condition, $r S$ is the air-gap variation at the position of the maximum air-gap length at mean radius Rav of the stator, and

$$
r_{S}=R_{a v} \sin \beta_{S} .
$$
[16]:

The air-gap length under SE fault is given by Reference

$$
g(\varphi)=g_{0}(1-\mathrm{SEF} \cdot \cos (\varphi-\gamma)),
$$

where $\varphi$ is the angle measured from a reference point and $\gamma$ is the reference point of minimum air-gap length. The dynamic eccentricity factor (DEF) is obtained as

$$
\mathrm{DEF}=\frac{r_{D}}{g_{0}} \times 100 \%,
$$

where $r_{\mathrm{D}}$ is the air-gap variation at the position of the maximum air-gap length at mean radius $R_{a v}$ of the rotor and

$$
r_{D}=R_{a v} \sin \beta_{D} .
$$

The expression of air-gap length at $R_{a v}$ can be obtained by introducing a time variable on the basis of equation (7), and it follows that

$$
g(\varphi, t)=g_{0}(1-\mathrm{DEF} \cdot \cos (\varphi-\gamma-\omega t)) .
$$

As shown in Figure 5(c), both the stator and rotor offset in the case of ME. The mixed eccentricity factor (MEF) is the sum of the mixed static eccentricity factor (MSEF) and the mixed dynamic eccentricity factor (MDEF), that is, MEF $=$ MSEF + MDEF, and the MSEF and MDEF are as follows:

$$
\begin{gathered}
\text { MSEF }=\frac{r_{M S}}{g_{0}} \times 100 \%, \\
\text { MDEF }=\frac{r_{M D}}{g_{0}} \times 100 \%,
\end{gathered}
$$

where $r_{M S}$ and $r_{M D}$ are the air-gap variation at the position of the maximum air-gap length at Rav of the stator and rotor, and they are obtained by

$$
\begin{aligned}
& r_{M S}=R_{a v} \sin \beta_{M S}, \\
& r_{M D}=R_{a v} \sin \beta_{M D} .
\end{aligned}
$$

And the MEF is

$$
\mathrm{MEF}=\frac{r_{M S}+r_{M D}}{g_{0}} \times 100 \% .
$$

The air-gap length at Rav in the case of ME is deduced as 


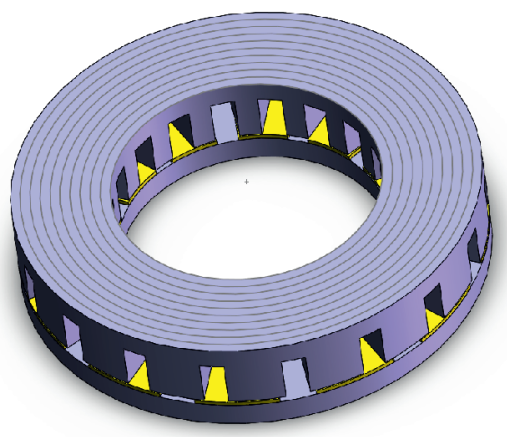

(a)

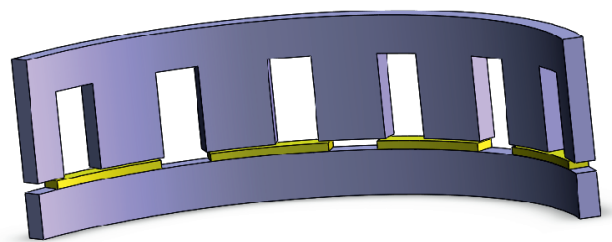

(b)

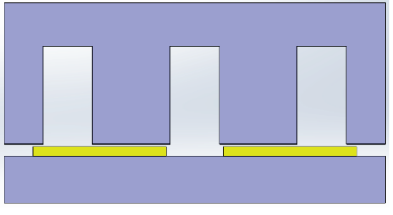

(c)

FIGURE 2: Modeling of an AFPM machine by the quasi-3D method. (a) N layers along the radial direction, (b) one layer taken to expand along the circumference direction, and (c) a pair of poles of the $2 \mathrm{D}$ model.

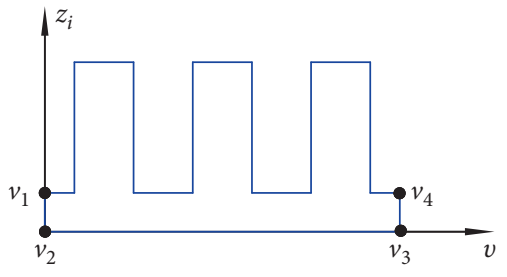

(a)

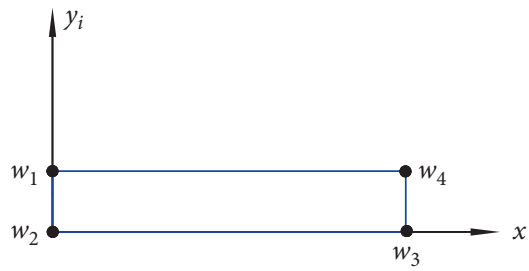

(b)

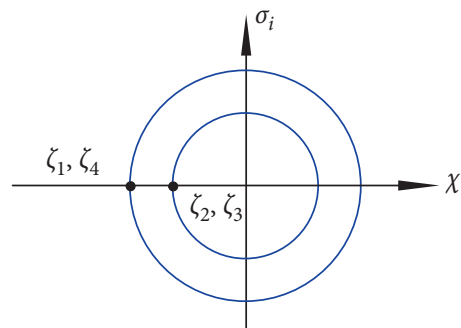

(c)

FIgURE 3: Schwarz-Christoffel mapping. (a) V-plane, $v=v+z i$; (b) W-plane, $w=x+y i$; and (c) T-plane, $\zeta=\chi+\sigma i$.

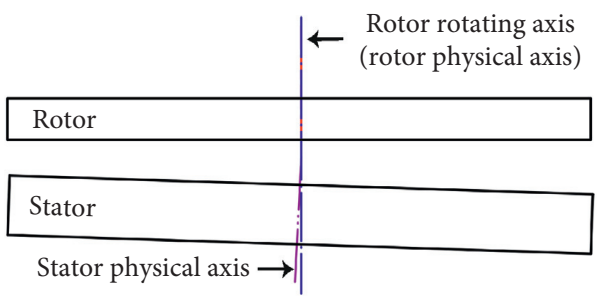

(a)

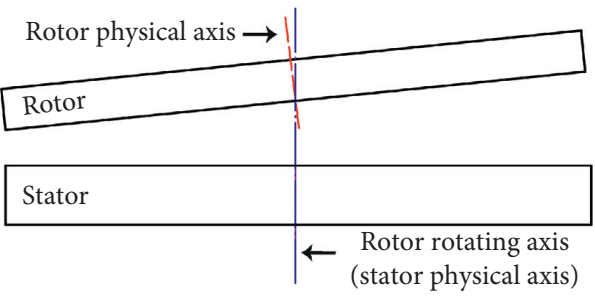

(b)

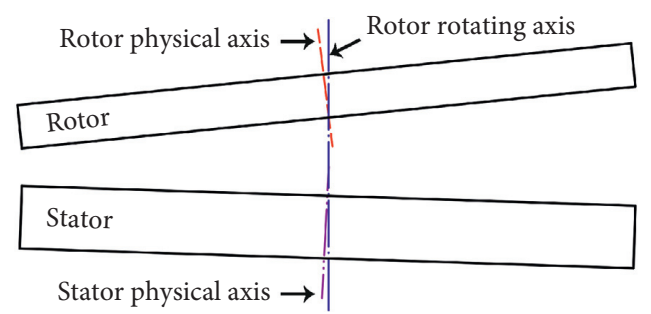

(c)

Figure 4: Eccentricity faults: (a) SE, (b) DE, and (c) ME.

$$
\begin{aligned}
g(\varphi, t)= & g_{0}(1-\mathrm{MDEF} \cdot \cos (\varphi-\gamma)) \\
& +g_{0}(1-\mathrm{MDEF} \cdot \cos (\varphi-\gamma-\omega t))-g_{0}, \\
& =g_{0}\{1-[\mathrm{MSEF} \cdot \cos (\varphi-\gamma)+\mathrm{MDEF} \cdot \cos (\varphi-\gamma-\omega t)]\} .
\end{aligned}
$$

Figure 6 shows the air-gap variation of the AFPM machine in the case of $\mathrm{SE}, \mathrm{DE}$, and $\mathrm{ME}(\mathrm{SEF}=30 \%$, $\mathrm{DEF}=40 \%$, and $\mathrm{MEF}=70 \%$, where $\mathrm{MSEF}=30 \%$ and $\mathrm{MDEF}=40 \%$ ).

As can be seen from Figure 6, in the case of SE, the airgap length is only related to the spatial position and does not 


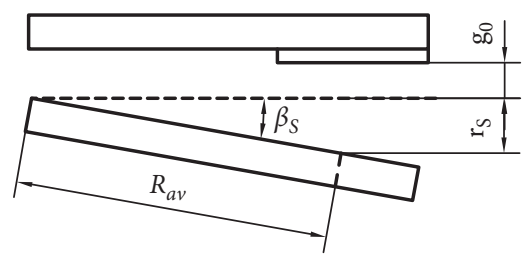

(a)

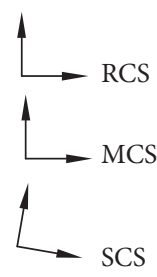

SCS

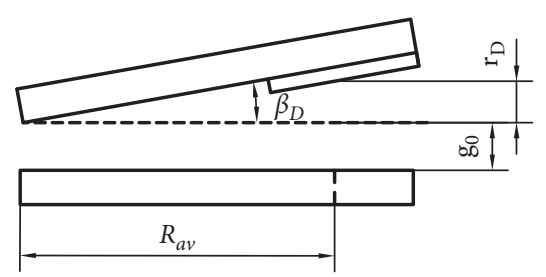

(b)

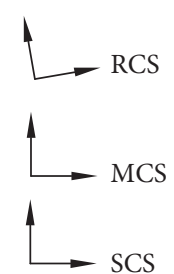

SCS

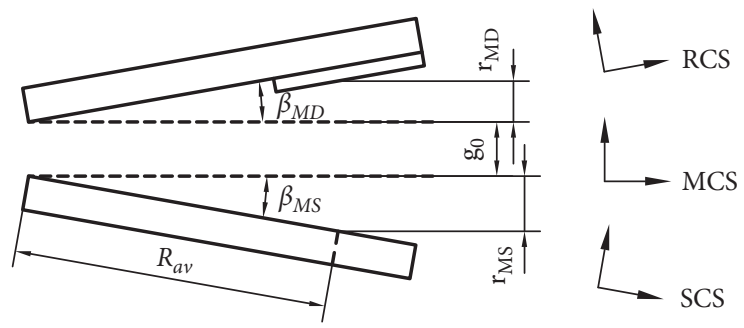

(c)

Figure 5: Parameters in the analysis of eccentricity: (a) SE, (b) DE, and (c) ME.

change with time. In the case of DE and ME, the air-gap length of a certain spatial position varies with time. When DE occurs, the maximum and minimum values of the airgap length at different times remain unchanged, but these two values vary with time in the case of ME, and the air-gap flux density and EFD of the machine will also be affected accordingly.

3.1. Air-Gap Magnetic Field. The eccentric AFPM machine model of V-plane is established in the CS. As shown in Figure 7, in order to describe the change of air-gap caused by the eccentricity, Schwarz-Christoffel mapping described above is used to obtain the air-gap flux density under the eccentricity fault by equation (2).

Because of the similarity in the calculation process of airgap flux density in SE, DE, and ME, the $\mathrm{DE}(\mathrm{DEF}=40 \%)$ is taken as an example to illustrate in detail. The calculation results are shown in Figure 8.

As shown in Figures 7 and 8, the results of flux density calculated by the SC and FEM coincide with each other, and EFD can be obtained from equations (3) and (4). That also verifies the validity of the proposed method in calculating electromagnetic force.

From the combination of Figures 7 and 8, it can be seen that the axial air-gap flux density has changed significantly under eccentric condition, and the tangential component is influenced, but to a lesser extent. In the range of 0-90 degrees, the axial component is smaller than that of the ideal condition, and the reduced value decreases with the increase of the mechanical angle.

In the range of 90-180 degrees, the air-gap length of the eccentricity state is less than that of the normal state, so the axial component of the air-gap flux density is larger than that of the normal state, and the increased value increases with the increase of the mechanical angle.
In order to describe the distortion degree of air-gap density corresponding to different EFs, the following formula can be obtained:

$$
\operatorname{THD}\left(\mathrm{EF}_{2}\right)=\operatorname{THD}\left(\mathrm{EF}_{1}\right)+\kappa\left(\mathrm{EF}_{2}-\mathrm{EF}_{1}\right)
$$

where $\operatorname{THD}\left(\mathrm{EF}_{2}\right)$ and $\operatorname{THD}\left(\mathrm{EF}_{1}\right)$ represent the THD of airgap density when the eccentricity factor is $\mathrm{EF}_{2}$ and $\mathrm{EF}_{1}$ and $\kappa$ is the slope which is used to describe the variation degree of THD from $\operatorname{THD}\left(\mathrm{EF}_{1}\right)$ to $\operatorname{THD}\left(\mathrm{EF}_{2}\right)$.

As shown in Figure 9, the $\kappa$ is all positive, which indicates that bigger THD occurs when the EF is bigger. When the EF varies from 0 to $0.1, \kappa$ is rather small, and that means the airgap density is influenced less when the EF is 0.1 . However, the value of $\kappa$ increases sharply when the EF increases to 0.2 . So, the EF should be limited to less than 0.1 for a less impact on air-gap density.

3.2. Electromagnetic Force. With reference to CS, the synthetic EFD of the AFPM machine is $f s$, and it can be expressed as

$$
\overrightarrow{f_{S}}=\overrightarrow{f_{z}}+\overrightarrow{f_{t}}
$$

In the following analysis, EFD is decomposed into axial and tangential components in different reference coordinate systems (SCS, MCS, and RCS). The analysis process for each of the three kinds of eccentricity is very similar to any of them, so only the transformation for ME is given in this paper, and the analysis for SE and DE can be easily done with the help of Figures 10(a) and 10(b).

For ME, the reference is RCS, when the force acting on the rotor is analyzed. And when analyzing the force acting on the stator, the reference is SCS. Referring to Figure 10(c), the expression of EFD in ME can be obtained. $f_{M s z}^{\prime}$ and $f_{M s t}^{\prime}$ are the axial and tangential components of the EFD acting on the stator, and $f_{M r z}^{\prime}$ and $f_{M r t}^{\prime}$ are those 


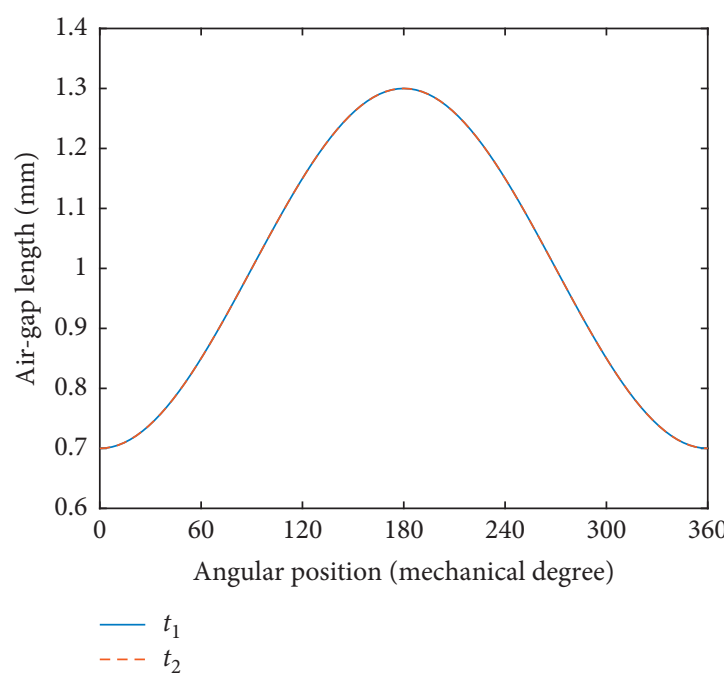

(a)

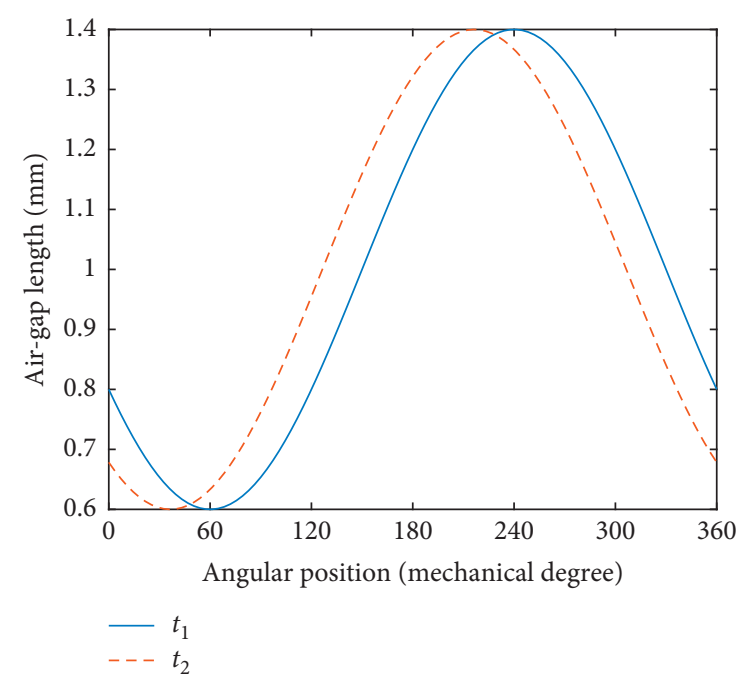

(b)

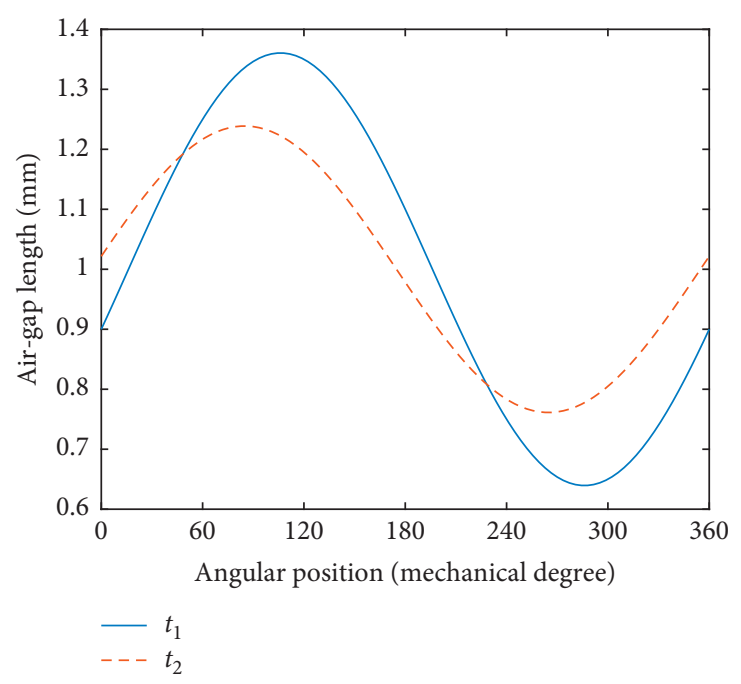

(c)

Figure 6: Air-gap variation of the AFPM machine: (a) SE, (b) DE, and (c) ME.

acting on the rotor. Then, the following expressions are easily obtained:

$$
\begin{aligned}
& f_{M s z}^{\prime}=f_{s} \cdot \sin \left(\beta_{M S}+\xi_{M S}\right), \\
& f_{M s t}^{\prime}=f_{s} \cdot \cos \left(\beta_{M S}+\xi_{M S}\right), \\
& f_{M r z}^{\prime}=f_{s} \cdot \cos \left(\beta_{M D}+\xi_{M D}\right), \\
& f_{M r t}^{\prime}=f_{s} \cdot \sin \left(\beta_{M D}+\xi_{M D}\right),
\end{aligned}
$$

where $\xi_{M S}=\left\langle f_{s}, f_{t}\right\rangle$ and $\xi_{M D}=\left\langle f_{s}, f_{z}\right\rangle$.

\section{Results and Discussion}

The EFD acting on the stator and rotor under different eccentricity faults can be depicted in Figures 11-19.

From the comparison among Figures 11-20, it can be seen that EFD of the AFPM machine is affected in any eccentricity fault, and the degree of the influence is related to the EF.

In Figures 11-19, the angular positions of the minimum air-gap length $g_{\min }$ and the maximum air-gap length $g_{\max }$ are as follows:

$$
\begin{array}{llll}
\text { SE: } & g_{\min }=0.7 \mathrm{~mm}, \quad \text { mechanical } & \text { degree: } & 0 ; \\
g_{\max }=1.3 \mathrm{~mm} \text {, mechanical degree: } 180 & & \\
\mathrm{DE}: & g_{\min }=0.6 \mathrm{~mm}, \quad \text { mechanical degree: } & 180 ; \\
g_{\max }=1.4 \mathrm{~mm}, \text { mechanical degree: } 0 & & \\
\mathrm{ME}: \quad g_{\min }=0.3 \mathrm{~mm}, \quad \text { mechanical } & \text { degree: } & 0 ; \\
g_{\max }=1.7 \mathrm{~mm}, \text { mechanical degree: } 180 & &
\end{array}
$$

From Figures 11-20, the followings conclusions can be drawn:

(1) As shown in Figures 11, 12, 14, 15, 17, and 18, the EFD increases at the position where the air-gap 


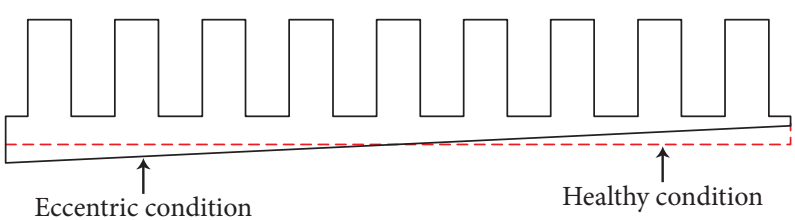

Figure 7: Eccentric AFPM machine model of the V-plane.

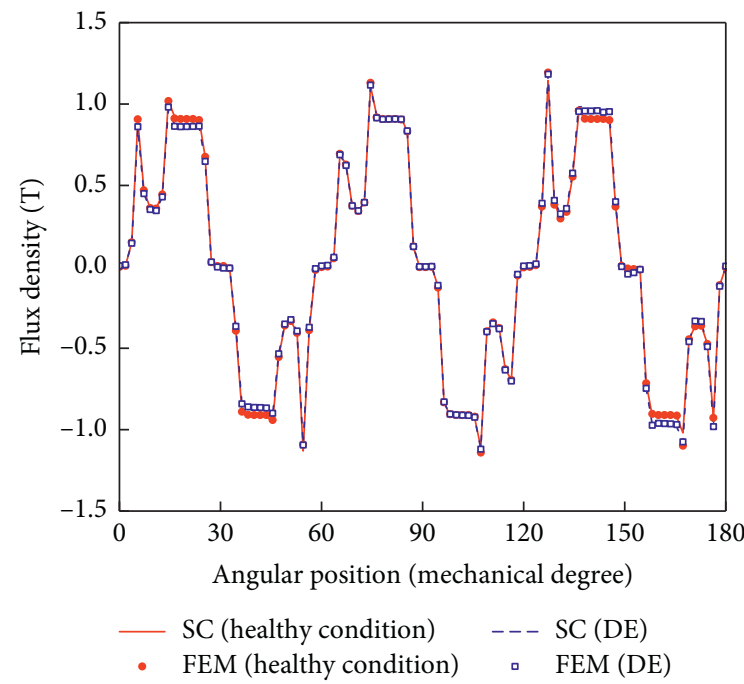

(a)

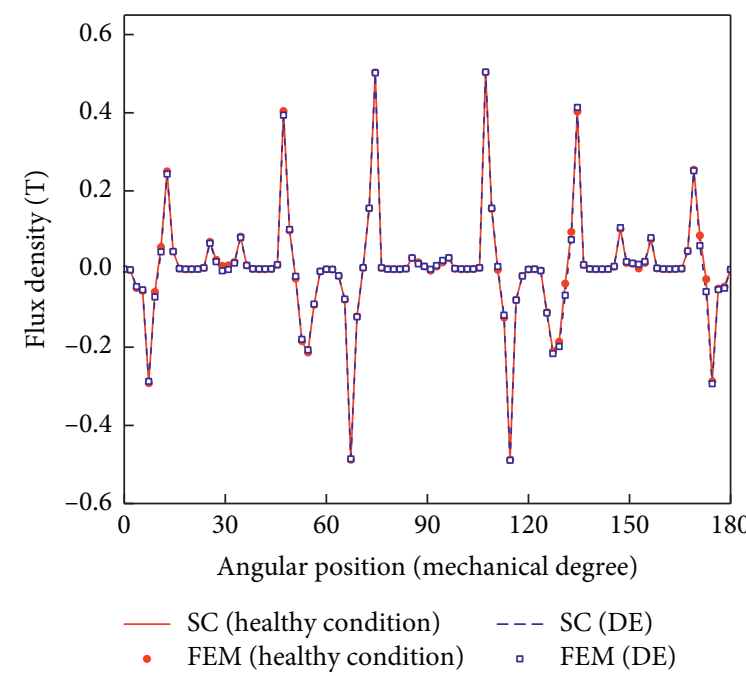

(b)

Figure 8: Axial (a) and tangential (b) components of the air-gap flux density in DE (DEF $=40 \%)$.

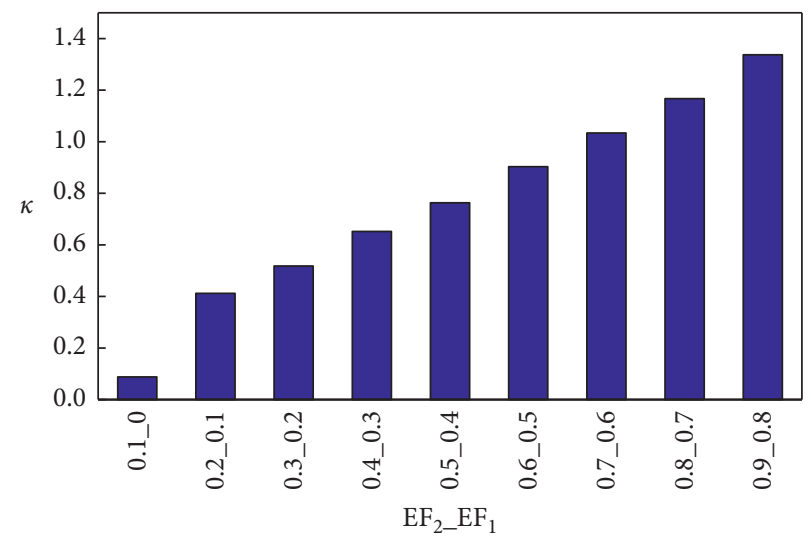

FIGURE 9: Variation of $\kappa$ with different EFs.

length decreases due to eccentricity and decreases at the position where the air-gap length increases. By comparing the (a) and (b) of Figures 11, 12, 14, 15, 17, and 18 with Figure 20, it can be seen that eccentricities have a greater impact on axial components of EFD rather than tangential components. And that can also be judged from the (c) of Figures $11,12,14,15,17$, and 18 . The main reason is that the axial EFD is proportional to the difference of the square of the axial and tangential flux density according to equation (3), and the tangential EFD is in direct proportion to the product of axial and tangential flux density on the basis of equation (4). Moreover, the results obtained from Figure 8 show that the axial flux density is much larger than the tangential in most locations. As a result, the axial component of EFD suffers a greater impact brought by eccentricity. 


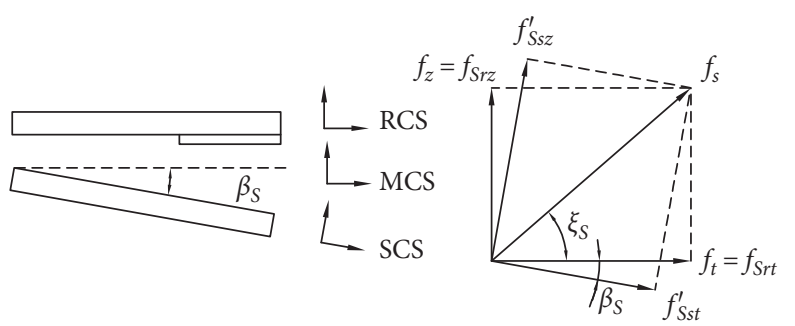

(a)
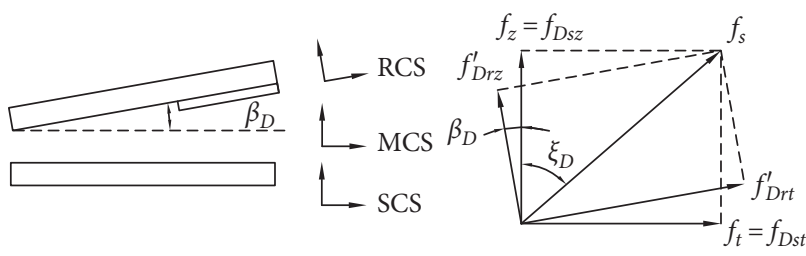

(b)

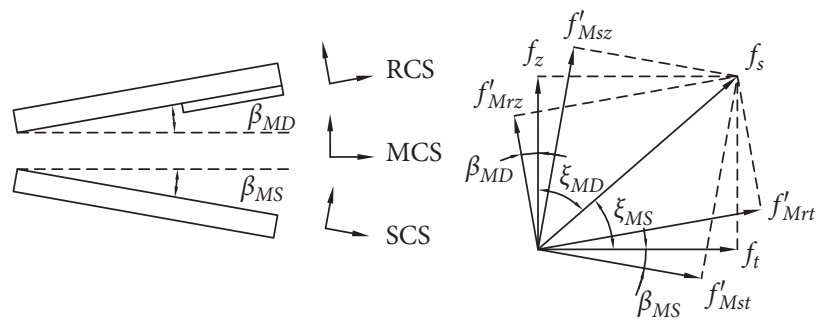

(c)

Figure 10: Decomposition of EFD: (a) SE, (b) DE, and (c) ME.

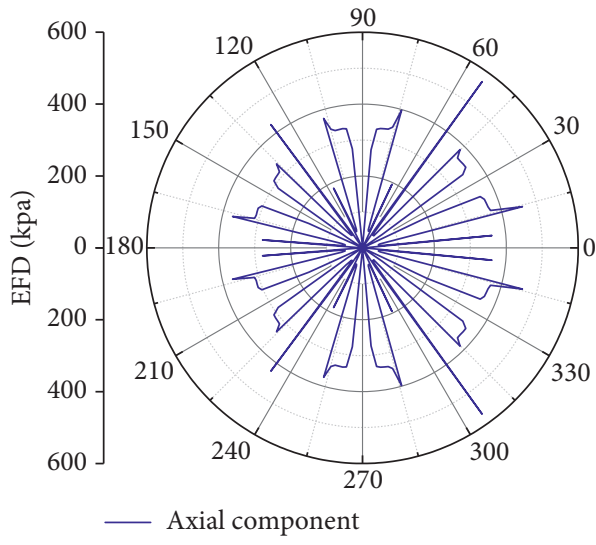

(a)

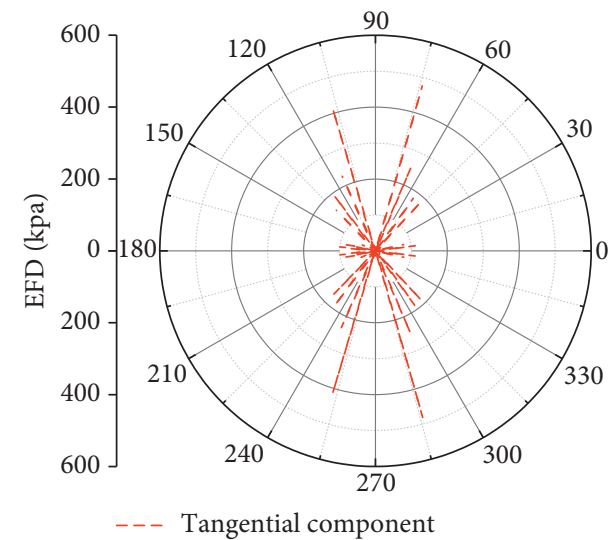

(b)

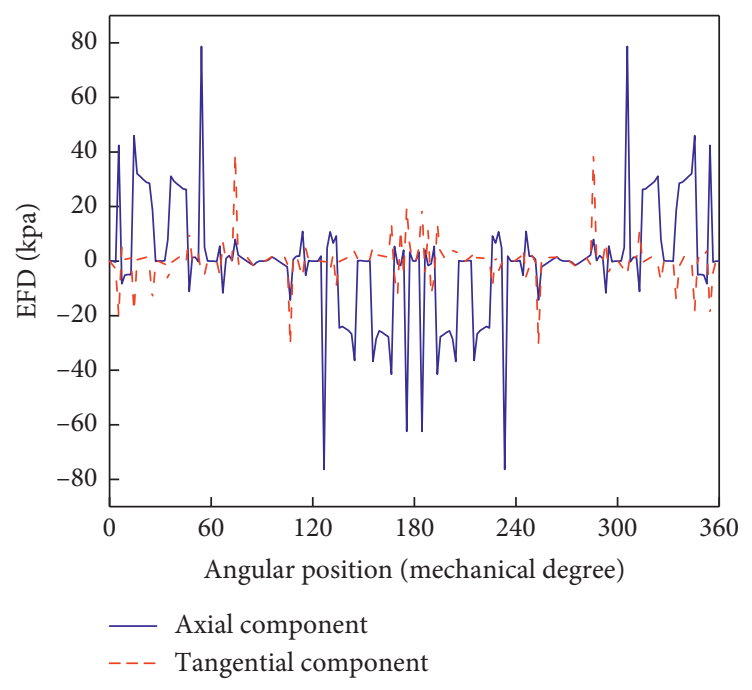

(c)

FiguRE 11: SE: EFD at different positions of the stator at $R=157.75 \mathrm{~mm}(\mathrm{SEF}=0.3)$, including axial (a) and tangential (b) components and (c) axial and tangential components of the difference with ideal condition. 


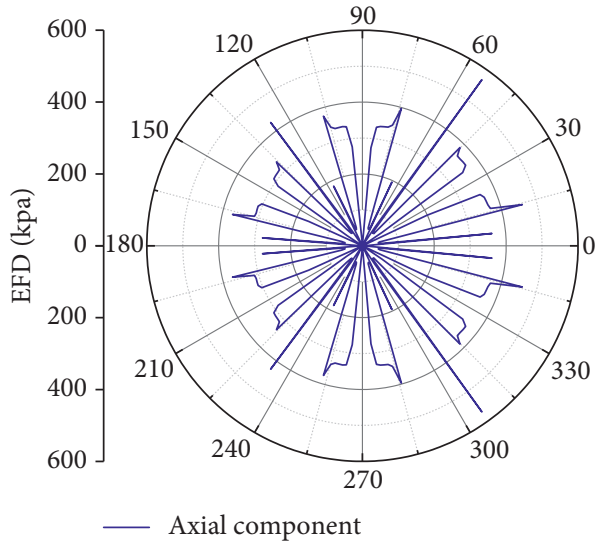

(a)

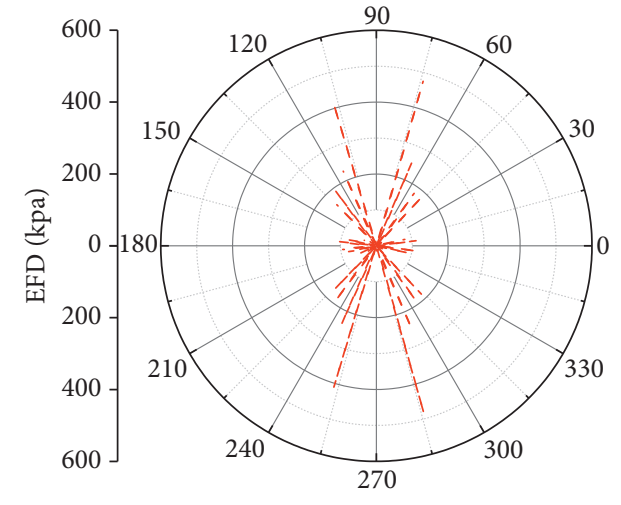

--_ Tangential component

(b)

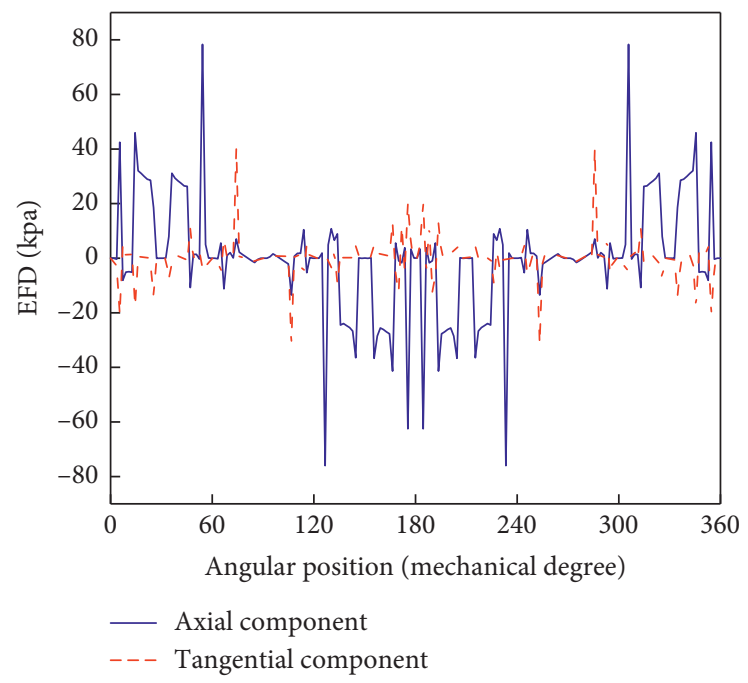

(c)

FIGURE 12: SE: EFD at different positions of the rotor at $R=157.75 \mathrm{~mm}(\mathrm{SEF}=0.3)$, including axial (a) and tangential (b) components and (c) axial and tangential components of the difference with ideal condition.

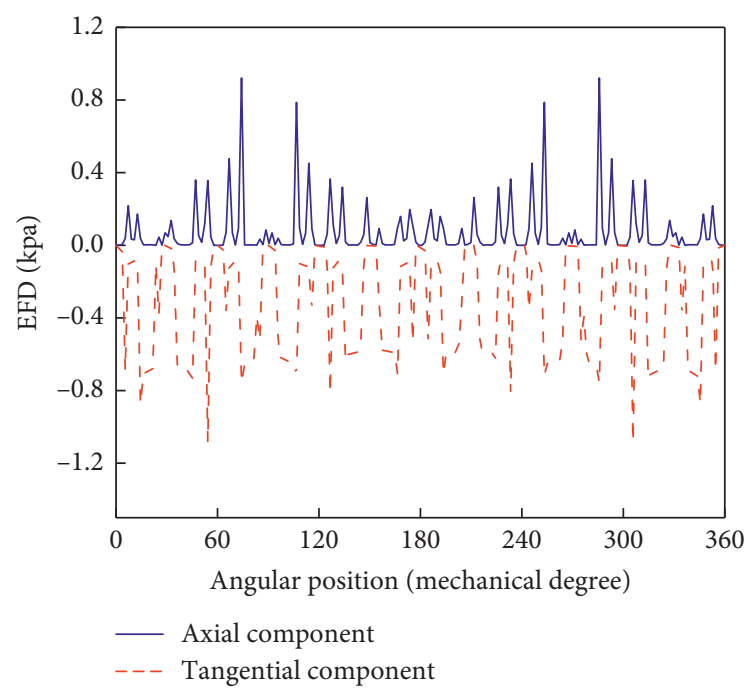

FIgURE 13: SE: Difference of EFD at different positions between the stator and rotor at $R=157.75 \mathrm{~mm}(\mathrm{SEF}=0.3)$. 


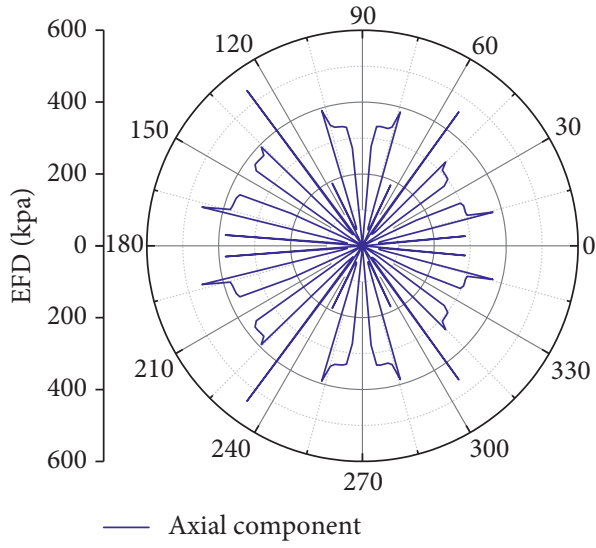

(a)

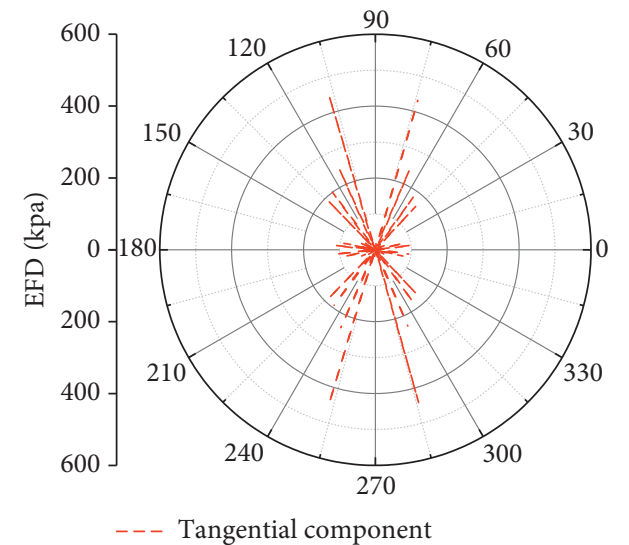

(b)

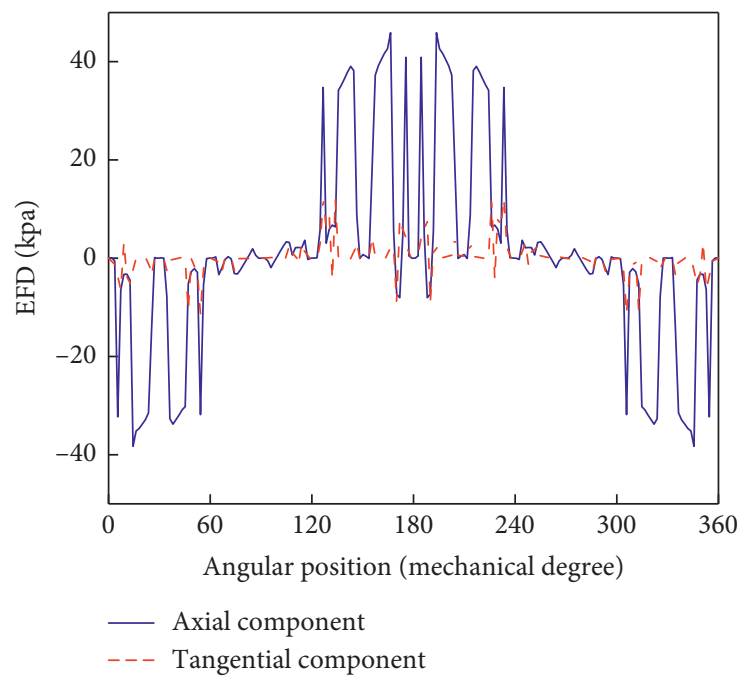

(c)

Figure 14: DE: EFD at different positions of the stator at $R=157.75 \mathrm{~mm}(\mathrm{DEF}=0.4)$, including axial (a) and tangential (b) components and (c) axial and tangential components of the difference with ideal condition.

(2) In the corresponding coordinate system, the axial force acting on the stator is larger than that acting on the rotor, and the tangential force acting on the stator is smaller. The results are consistent with the analysis in Figure 10. Therefore, attention should be paid to the axial force acting on the stator when eccentricity occurs. In practical application, a thrust bearing with supporting axial load capacity can be installed in the stator.

(3) The EFs in the three kinds of eccentricity are different: $\mathrm{SEF}=0.3, \mathrm{DEF}=0.4$, and $\mathrm{MEF}=0.7$. Among the three eccentricities, the variation of the EFD under $\mathrm{ME}$ is the largest because of its largest EF. The larger the EF, the larger the air-gap length changes. So, the air-gap density and the EFD will be more affected. So, if eccentricity faults cannot be avoided in practical use, measures such as improving assembly accuracy should be taken to weaken the degree of eccentricity.
In addition, there are still some issues about the EFD worth discussing. Taking DE as an example as before, the following research is done.

As shown in Figure 21, EFD varies linearly with radius. On the air-gap reduction side, outer position's EFD is larger than the inner one's because of the gradual reduction of airgap length, while it does the opposite on the air-gap enlargement side.

When solving the EFD under eccentric conditions within one electrical period, the proposed analytical method takes 2 minutes to calculate, while the 3D FEM takes 12 hours to complete the calculation. So, the computation time of the proposed analytical method is much less than that of the FEM. The proposed analytical method can be a useful tool for analyzing AFPM machines.

When eccentricity occurs, the air-gap field is distorted, which makes the axial EFD distorted compared with that of ideal condition. The spatial decomposition of axial EFD is done under both ideal and eccentricity 


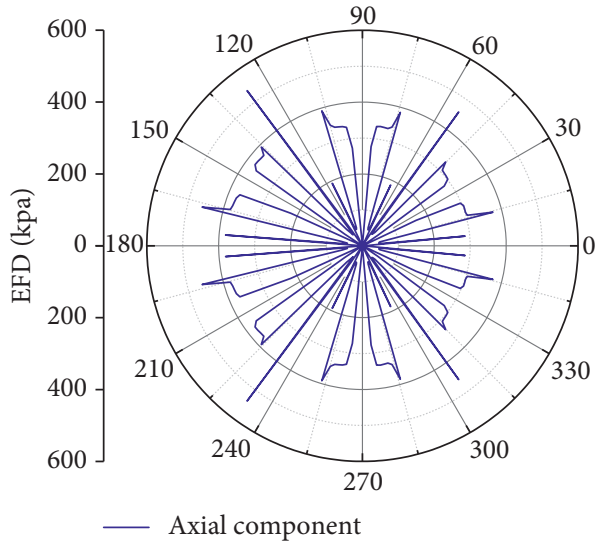

(a)

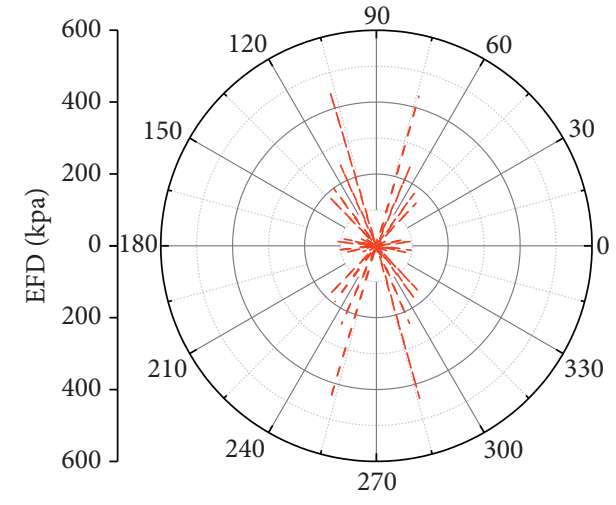

- - - Tangential component

(b)

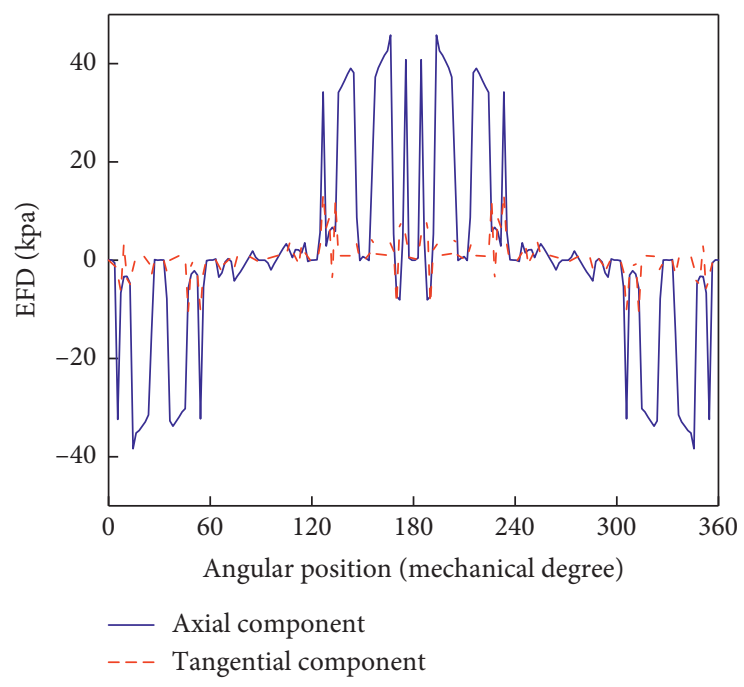

(c)

Figure 15: DE: EFD at different positions of the rotor at $R=157.75 \mathrm{~mm}(\mathrm{DEF}=0.4)$, including axial (a) and tangential (b) components and (c) axial and tangential components of the difference with ideal condition.

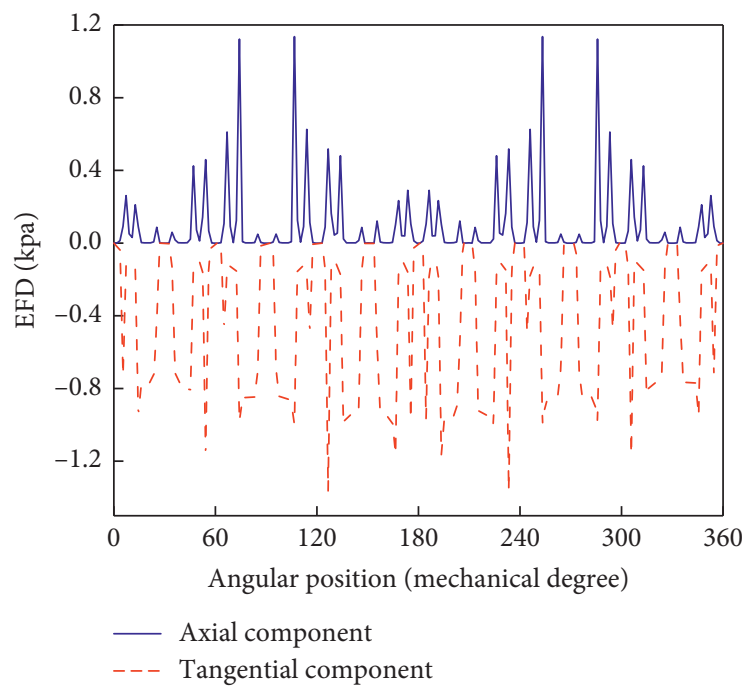

FIgure 16: DE: Axial and tangential components of the difference of EFD at different positions between the stator and rotor at $R=157.75 \mathrm{~mm}(\mathrm{DEF}=0.4)$. 


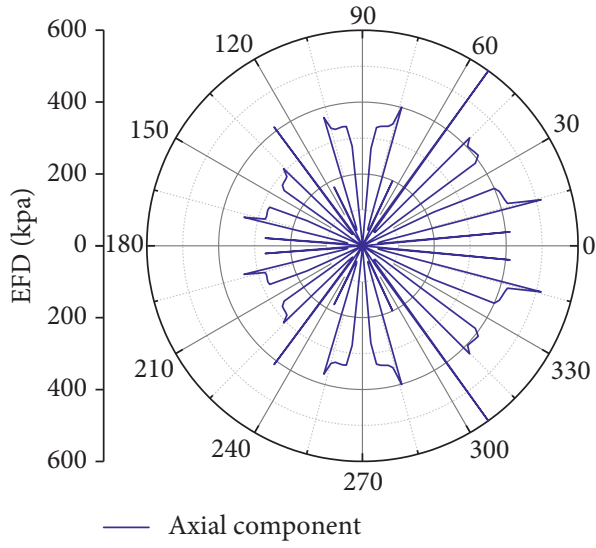

(a)

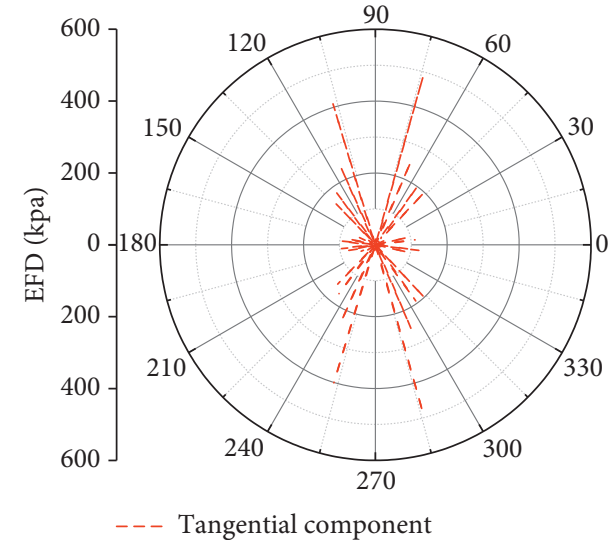

(b)

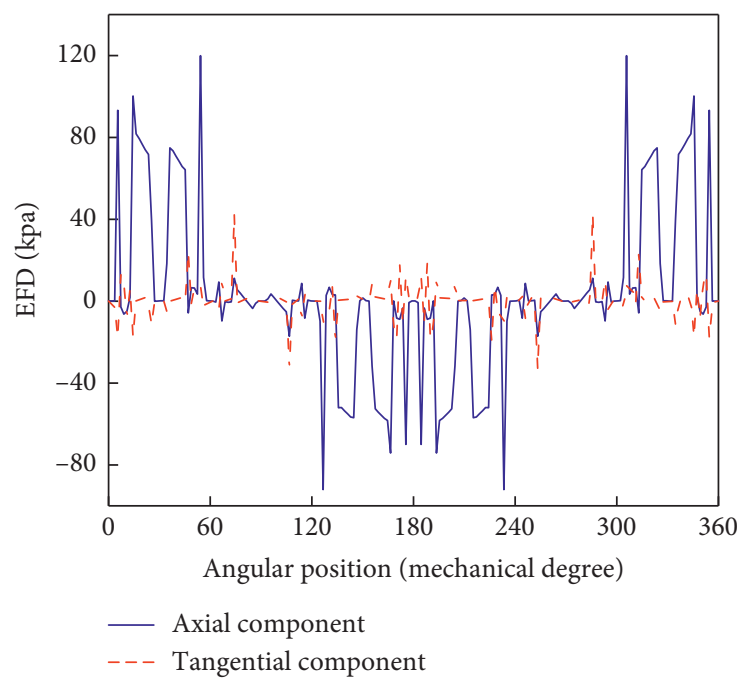

(c)

Figure 17: ME: EFD at different positions of the stator at $R=157.75 \mathrm{~mm}(\mathrm{MEF}=0.7)$, including axial (a) and tangential (b) components and (c) axial and tangential components of the difference with ideal condition.

conditions, and the main spatial order is given in Figure 22. On the basis of the original spatial order, the \pm 1 and \pm 2 components appear because of the eccentricity. And the EFD magnitude of the \pm 2 order is relatively small. Some of the extra spatial orders of axial EFD will be closer to the lower orders of the stator, which will aggravate the vibration of the motor. The change of EFD caused by eccentricity will affect the vibration and noise characteristics of the motor.

Open slot structures are more favorable for manufacturing. As shown in Figure 22, the large harmonic amplitude of axial EFD will aggravate the vibration of the motor. In motor design, it has been demonstrated in References [17] and [18] that magnetic wedges can improve performance of the machine in an all-round way. In order to avoid excessive shunting of the permanent magnet flux, the machine with semiclosed slots under eccentricity condition is investigated.

The spatial order of EFD of the original model (Figure 23(a).) and the model with a magnetic wedge (Figure 23(b)) is illustrated in Table 2. In Table 2, it is shown that all the spatial harmonics except the 12th order are smaller when the stator slots are semiclosed. Especially, the original sixth harmonic with a smaller order and larger amplitude has been weakened obviously. Therefore, when eccentricity occurs, vibration of the AFPM with semiclosed slots will be significantly lower than that of the AFPM with open slots. 


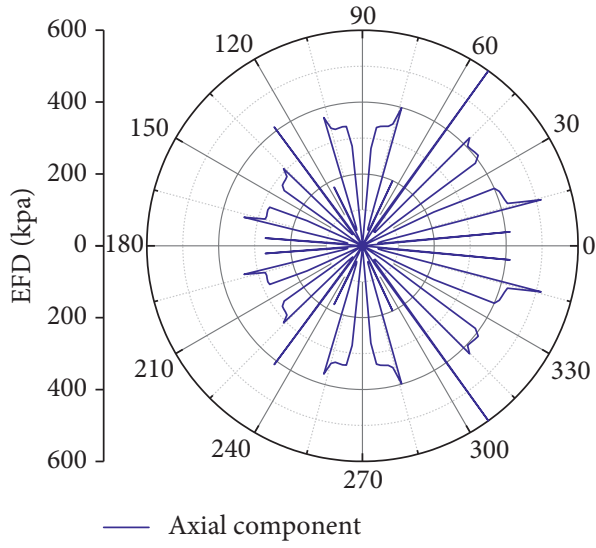

(a)

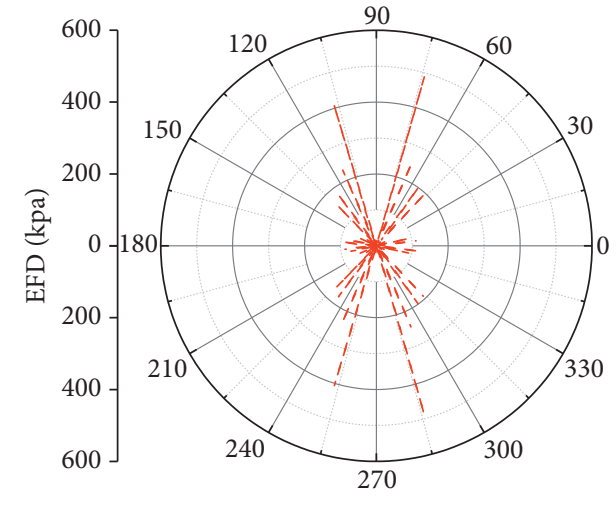

- - Tangential component

(b)

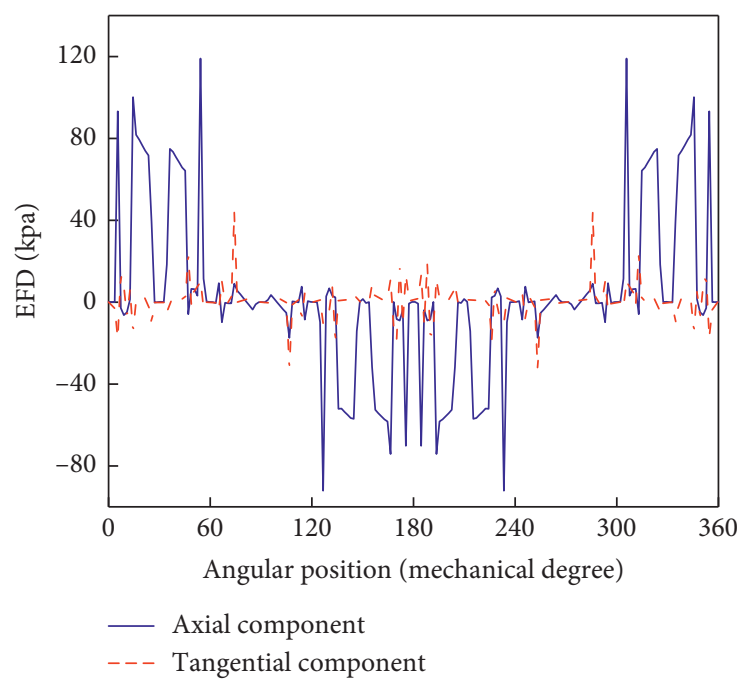

(c)

Figure 18: ME: EFD at different positions of the rotor at $R=157.75 \mathrm{~mm}(\mathrm{MEF}=0.7)$, including axial (a) and tangential (b) components and (c) axial and tangential components of the difference with ideal condition.

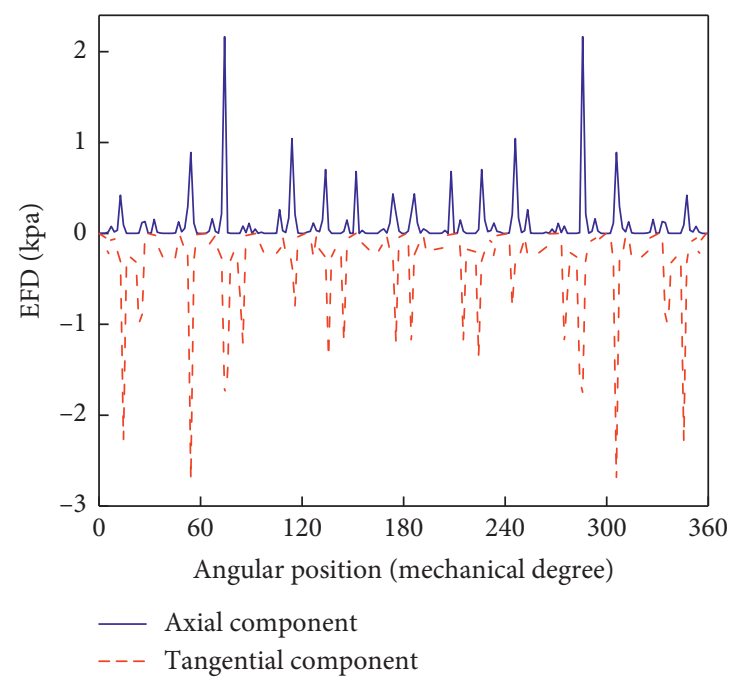

Figure 19: ME: Axial and tangential components of the difference of EFD at different positions between the stator and rotor at $R=157.75 \mathrm{~mm}(\mathrm{MEF}=0.7)$. 


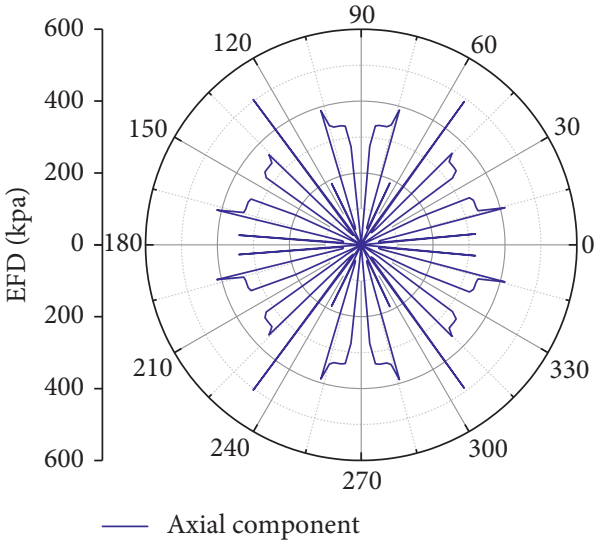

(a)

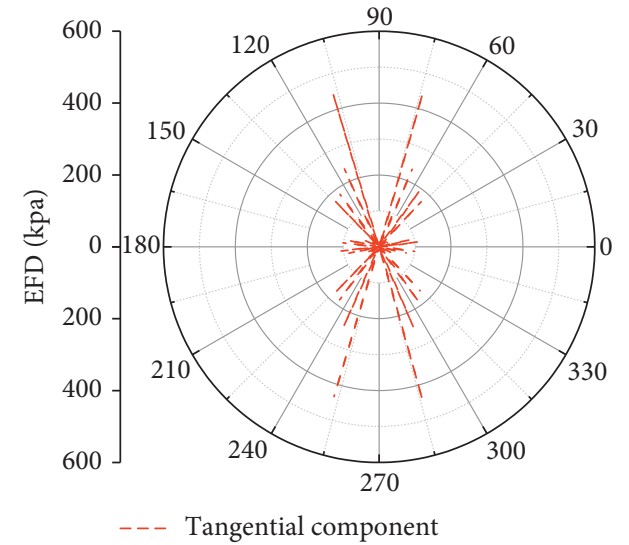

(b)

Figure 20: Axial and tangential components of the EFD at $R=157.75 \mathrm{~mm}$ under ideal condition.

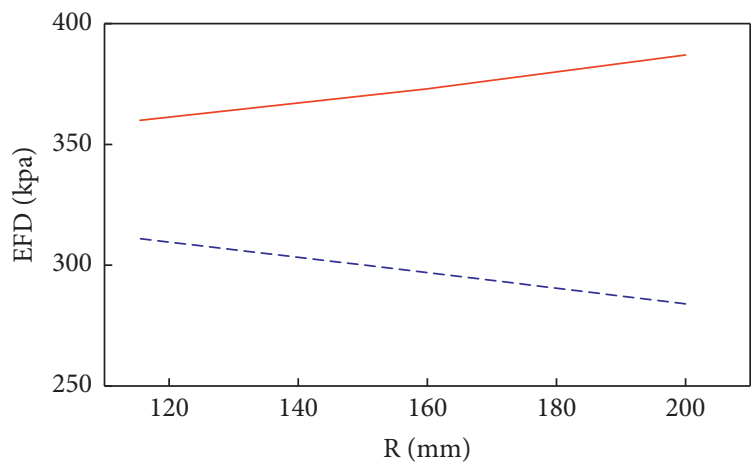

_ Air-gap reduction side

--- Air-gap enlargement side

Figure 21: EFD at different radii.

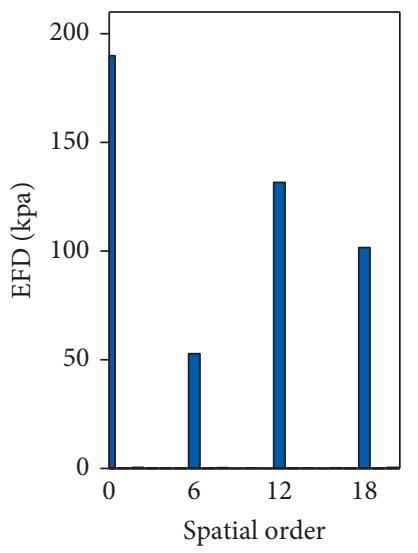

(a)

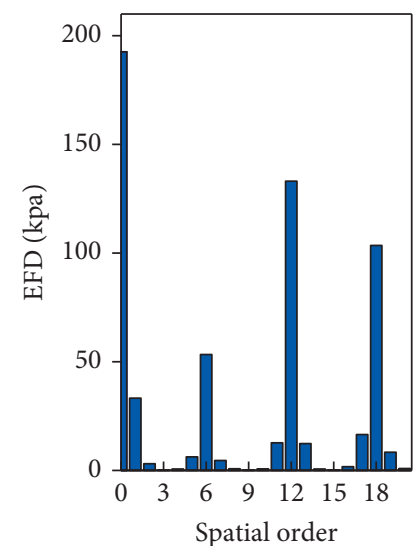

(b)

FIgURE 22: Spatial decomposition of EFD: (a) ideal condition and (b) eccentricity condition. 


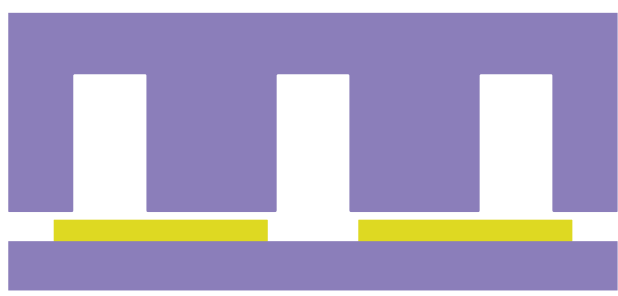

(a)

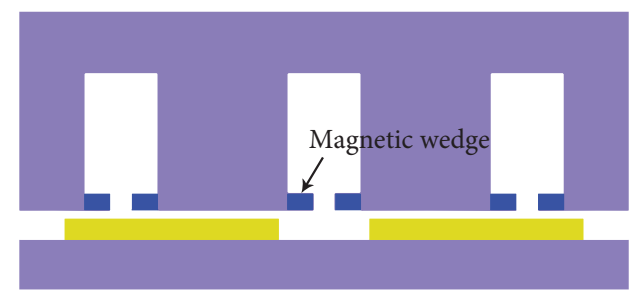

(b)

Figure 23: Open slot (a) and semiclosed slot (b) 2D models.

TABLE 2: Spatial orders of EFD of the open slot and the semiclosed slot AFPM machine.

\begin{tabular}{|c|c|c|c|c|c|c|}
\hline Spatial order & 1 & 2 & 4 & 5 & 6 & 7 \\
\hline Open slot & 33 & 3.07 & 0.62 & 6.21 & 53.3 & 4.6 \\
\hline Semiclosed slot & 32.3 & 0.46 & 0.59 & 0.27 & 5.12 & 0.5 \\
\hline Spatial order & 8 & 10 & 11 & 12 & 13 & 14 \\
\hline Open slot & 0.93 & 0.73 & 12.7 & 133.1 & 12.3 & 0.6 \\
\hline Semiclosed slot & 0.75 & 0.49 & 11.87 & 144.4 & 11.8 & 0.4 \\
\hline Spatial order & 16 & 17 & 18 & 19 & 20 & \\
\hline Open slot & 1.7 & 16.4 & 103.5 & 8.3 & 0.9 & \\
\hline Semiclosed slot & 0.9 & 1.4 & 10.8 & 0.8 & 0.6 & \\
\hline
\end{tabular}

\section{Conclusions}

This paper introduced a fast analytical method to study the electromagnetic force of eccentric AFPM machines, and the results are verified by the FEM. The analytical method is based on the Schwarz-Christoffel mapping and MST method. The expression of air-gap length in ME is obtained. EFD is used to characterize the variation of electromagnetic force. EFD is decomposed into axial and tangential components in different reference coordinate systems (SCS, MCS, and RCS) during the analysis of electromagnetic force acting on the stator and rotor. The method can be used in different eccentricities, including SE, DE, and ME. The distribution law of electromagnetic force under different eccentricity conditions is summarized to facilitate further research on motor design, eccentricity detection, and so on. The method presented in this paper has a strong universality and is applicable to AFPM machines under both eccentric and ideal conditions.

\section{Data Availability}

All data included in this study are available upon request to the corresponding author.

\section{Conflicts of Interest}

The authors declare no conflicts of interest.

\section{References}

[1] M. Aydin, S. Surong Huang, and T. A. Lipo, "Torque quality and comparison of internal and external rotor axial flux surface-magnet disc machines," IEEE Transactions on Industrial Electronics, vol. 53, no. 3, pp. 822-830, 2006.
[2] D. K. Lim, Y. S. Cho, J. S. Ro, S. Y. Jung, and H. K. Jung, "Optimal design of an axial flux permanent magnet synchronous motor for the electric bicycle," IEEE Transactions on Magnetics, vol. 52, no. 3, 2016.

[3] C. Kim, G. Jang, J. Kim, J. Ahn, C. Baek, and J. Choi, "Comparison of axial flux permanent magnet synchronous machines with electrical steel core and soft magnetic composite core," IEEE Transactions on Magnetics, vol. 53, no. 11, 2017.

[4] W. Deng and S. Zuo, "Axial force and vibroacoustic analysis of external-rotor axial-flux motors," IEEE Transactions on Industrial Electronics, vol. 65, no. 3, pp. 2018-2030, 2018.

[5] L. Zeng, X. Chen, W. Li, X. Jiang, and X. Luo, "A thrust force analysis method for permanent magnet linear motor using Schwarz-Christoffel mapping and considering slotting effect, end effect, and magnet shape," IEEE Transactions on Magnetics, vol. 51, no. 9, pp. 1-9, 2015.

[6] A. D. Gerlando, G. M. Foglia, M. F. Iacchetti, and R. Perini, "Evaluation of manufacturing dissymmetry effects in axial flux permanent-magnet machines: analysis method based on field functions," IEEE Transactions on Magnetics, vol. 48, no. 6, pp. 1995-2008, 2012.

[7] B. M. Ebrahimi, J. Faiz, and M. J. Roshtkhari, "Static-, dynamic-, and mixed-eccentricity fault diagnoses in permanentmagnet synchronous motors," IEEE Transactions on Industrial Electronics, vol. 56, no. 11, pp. 4727-4739, 2009.

[8] M. Aydin and M. Gulec, "A new coreless axial flux interior permanent magnet synchronous motor with sinusoidal rotor segments," IEEE Transactions on Magnetics, vol. 52, no. 7, p. $8105204,2016$.

[9] D. Kim, M. Noh, and Y. W. Park, "Unbalanced magnetic forces due to rotor eccentricity in a toroidally-wound BLDC motor," IEEE Transactions on Magnetics, vol. 52, no. 7, p. 8203204, 2016.

[10] T. A. Driscoll and L. N. Trefethen, Cambridge Monographs on Applied and Computational Mathematics, Cambridge University Press, Cambridge, U.K, 2002.

[11] X. H. Wang, Q. F. Li, S. H. Wang, and Q. F. Li, “Analytical calculation of air-gap magnetic field distribution and 
instantaneous characteristics of brushless DC motors," IEEE Transactions on Energy Conversion, vol. 18, no. 3, pp. 424-432, 2003.

[12] A. Alipour and M. Moallem, "Analytical magnetic field analysis of axial flux permanent-magnet machines using Schwarz-Christoffel transformation," in Proceedings of the 2013 International Electric Machines \& Drives Conference, pp. 670-677, Chicago, IL, USA, May 2013.

[13] F. Rezaee-Alam, B. Rezaeealam, and J. Faiz, "Unbalanced magnetic force analysis in eccentric surface permanentmagnet motors using an improved conformal mapping method," IEEE Transactions on Energy Conversion, vol. 32, no. 1, pp. 146-154, 2017.

[14] B. Guo, Y. Huang, and F. Peng, "An improved conformal mapping method for static angular eccentricity analysis of axial flux permanent magnet machines," Journal of Magnetics, vol. 23, no. 1, pp. 27-34, 2018.

[15] A. Parviainen, M. Niemela, and J. Pyrhonen, "Modeling of axial flux permanent-magnet machines," IEEE Transactions on Industry Applications, vol. 40, no. 5, pp. 1333-1340, 2004.

[16] S. M. Mirimani, A. Vahedi, F. Marignetti, and R. Di Stefano, "An online method for static eccentricity fault detection in axial flux machines," IEEE Transactions on Industrial Electronics, vol. 62, no. 3, pp. 1931-1942, 2015.

[17] G. D. Donato, F. G. Capponi, and F. Caricchi, "Influence of magnetic wedges on the no-load performance of axial-flux permanent-magnet machines," Proceedings of 2010 IEEE International Symposium on Industrial Electronics, vol. 27, pp. 1333-1339, 2010.

[18] G. D. Donato, F. G. Capponi, and F. Caricchi, "Influence of magnetic wedges on the load performance of axial-flux permanent-magnet machines," Proceedings of 36th Annual Conference on IEEE Industrial Electronics Society, vol. 24, pp. $876-882,2010$. 